\title{
Grafitos históricos murarios de la Cuesta del pescado no 16-18, en el Barrio del Realejo (Gra- nada)
}

\author{
Elena Navas Guerrero \\ Antonio Garrido Carrillo \\ Universidad de Granada
}

Artículo recibido: 2-3-2012 / Aceptado: 8-6-2012

Resumen: Se han identificado un total de 70 grafitos $^{1}$ históricos, realizados en el revoco original de dos casas del Barrio del Realejo de Granada. Los inmuebles están situados en el entorno de la antigua muralla medieval, junto a la desaparecida Puerta del Pescado, ubicada al sur de la Medina. La cronología del edificio es de principios del s.XIX. Los grafitos son de una gran variedad temática, siendo los más numerosos las representaciones de barcos, figuras femeninas con miriñaques, círculos trazados a compás y elementos de cuentas; aunque también hay cruces, elementos arquitectónicos, escritura, corazones, etc.

Palabras clave: Arqueología, estudio de paramentos, estratigrafía muraria, grafitos históricos, miriñaques, barcos.

RÉsumÉ: On a identifié 70 graffitis historiques, réalisés dans les murs originaux de deux maisons à Granada (Espagne). Les bâtiments sont situés au quartier historique du Realejo, prés d'où étaient les vieux murs médiévaux, à côté de la porte du Poisson, au Sud de la ville et déjà disparu. La chronologie des édifices est au début du XIXe siècle. Les graffitis sont d'une grande variété de thèmes; étant les représentations les plus nombreuses des navires, des figures féminines qui portent crinolines, des cercles décoratif et des éléments des comptes, mais il y a aussi des croix, des éléments architecturaux, d'écriture, des coeurs, etc.

Mots-clés: Archéologie, examen stratigraphique des murs, graffitis, crinoline, navires.

\section{INTRODUCCIÓN}

La intervención arqueológica, requerida para la rehabilitación de un edificio ${ }^{2}$

${ }^{1}$ Utilizaremos el término que recoge la Real Academia Española, que designa a Grafito la definición de "escrito o dibujo hecho a mano por los antiguos en los monumentos", aunque en el lenguaje común se utilice la palabra grafiti. situado en la C/ Cuesta del Pescado, en el barrio histórico del Realejo de Granada, ha puesto de manifiesto la existencia -en los muros internos del inmueble- de numerosos grafitos de origen histórico.

\footnotetext{
${ }^{2} \mathrm{El}$ Inmueble en realidad está compartimentado en dos casas individuales, con puertas de acceso, escaleras y número de parcela propias cada una de ellas.
} 
El edificio es de gran interés en el conjunto urbano, pues ocupa el espacio donde estuvo situada la Puerta del Pescado, una de las aperturas en la muralla de la antigua Medina medieval. La edificación sobresale de la alineación actual, y sin contar con un valor arquitectónico especial, contribuye a la configuración del lugar -significativo a escala de barrio- ya que es cabecera de manzana y punto focal de perspectivas de interés en un espacio público urbano.

La cronología del edificio restaurado es de comienzos del s.XIX, puesto que encontramos en la fachada una numeración anterior a la que aparece en un plano del proyecto de alineación de la Cuesta del Pescado, redactado por el Ayuntamiento de Granada en 1869, en el que sus números aparecen como 12 y 14, y que aún hoy en día se conservan esgrafiados en unas pequeñas losas de mármol situadas sobre las puertas de entrada de las viviendas ${ }^{3}$.

\section{CARACTERÍSTICAS DEL INMUEBLE}

El edificio alberga dos unidades de vivienda unifamiliar, ambas con acceso directo desde la C/ Cuesta del Pescado, a la que dan cara tres fachadas revestidas con ladrillo y decoradas con cajetones de mampuesto. Los vanos de las ventanas son de pequeño tamaño (en proporción a los muros) y de medidas irregulares. La cornisa es de ladrillo; la cubierta de teja árabe a cuatro aguas con fuerte pendiente. Tiene tres plantas, formando una nave de una sola crujía sin patio interior.

Las dos casas comparten el mismo tejado, con un único armazón de vigas de madera que se encuentran en muy buen estado de conservación, sirviendo la segunda planta como atroje, donde algunos tabiques no

\footnotetext{
${ }^{3}$ El estudio de paramentos de la fachada, dio como resultado la documentación de una numeración más antigua de la vivienda, con el no 39 , plasmada en una losa de cerámica y adornada con una cruz pomada. Esta numeración es anterior al derribo de la Puerta medieval, que se produjo en 1840, cuando los números de las casas arrancan intramuros y acaban en la misma Puerta de la antigua muralla.
}

llegan al techo. Al interior, los vanos de las ventanas se encuentran biselados para salvar el grosor de los muros, que son de tapial con ripio y revestidos con ladrillos macizos, entre pilares de ladrillo que no sobresalen. La compartimentación interna del espacio se hace con tabiques de ladrillo colocado a panderete, entre maderos dispuestos en vertical para evitar que cimbreen. Sobre el yeso aplicado como revestimiento, hay numerosas capas de cal, con variada coloración, incluyendo el rojo a la almagra. Sobre la gruesa capa de yeso del revoco original, se han encontrado numerosos grafitos históricos.

La complejidad de este espacio, de su uso y modificaciones a lo largo del tiempo, queda reflejada en el muro que sirve de medianería con los edificios colindantes. La planta baja presenta un revestimiento de piedra ${ }^{4}$, con losas de caliza fosilífera, procedente de las canteras de piedra histórica de Alfacar (Granada).

Adosado por el sureste a las losas de piedra, ha quedado la impronta de un edificio de tradición morisca que conserva un muro de mampuesto. Sobre el mismo, se dispone un alzado de tapial, en el que se abre una hornacina tabicada. Al eliminar el tabique, se pudo comprobar que se trataba de una taca, con un arco de herradura y con el interior revocado de yeso blanco. Su situación al sureste, en torno a los $110^{\circ}$, sugiere que podría utilizarse para ayudar a orientarse en el momento de la oración.

La fachada exterior presenta una interrupción en la esquina suroeste del edificio, tanto en el revestimiento como en los vanos, quizá porque estaba adosado a la antigua Puerta del Pescado. La esquina suroeste está rehecha en todo el tramo correspondiente a la planta baja, con numerosas losas de arenisca reutilizadas ${ }^{5}$; la esquina noroeste del

\footnotetext{
${ }^{4}$ Las losas tienen unas medidas de $80 \mathrm{~cm}$ de largo $\mathrm{x}$ $30 \mathrm{~cm}$ de ancho y con un grosor de $27 \mathrm{~cm}$. Tienen estrías hechas a propósito para que el agua de la lluvia pueda escurrir; por tanto, en origen es un muro exterior.

${ }^{5}$ La piedra de arenisca procede de las canteras de piedra histórica de La Malá (Granada), seguramente
} 
edificio está rematada con una pilastra de sillares de caliza fosilífera que mide $1.77 \mathrm{~m}$ de alto, también reutilizada.

\section{CONTEXTO HISTÓRICO}

Según se desprende de las fuentes documentales y arqueológicas, la ocupación más antigua de esta zona se produce en Época Medieval, cuando el crecimiento de la Medina musulmana hace que se desarrollen diversos arrabales en la orilla este del río Darro, extendiéndose por la zona comprendida entre los ríos Darro y Genil, lugar que hasta entonces había estado ocupado, primero por algunas almunias con sus huertas y campos de cultivo, y más tarde por actividades artesanales como la alfarería y tenerías. Uno de estos arrabales era el de al-Nayd, que significa "La Loma”, que en Época Nazarí se encuentra totalmente desarrollado. El nombre es muy significativo, ya que hace referencia a la orografía tan característica que aún hoy día se percibe en el actual barrio del Realejo, que presenta una elevación sobre el cauce del río Genil.

El barrio se consolida con la construcción de una muralla. Antes de que se derribara, algunos autores dejaron testimonio sobre las puertas de comunicación exterior, hacia el río Genil; una de ellas era la Bab alHayar (Puerta de la Piedra), conocida como Puerta del Pescado y situada en la cuesta del mismo nombre.

Con antelación a que la ciudad se expandiera por el actual Realejo, ya existían algunas almunias pertenecientes a familias dirigentes, que en Época Nazarí, pasarán a formar parte de los bienes de la familia real ${ }^{6}$. Un ejemplo de ello lo constituye la yannat al-Manyara al-Kubra o Huerta Grande de la

son restos de la antigua Puerta del Pescado, que tras su demolición, se reutilizaron como material de construcción, para reforzar las esquinas de la nueva fachada. Algunos sillares de arenisca están trabajados, incluso uno de ellos, en su momento, fue la imposta de nacela de arranque de un arco.

${ }^{6}$ De ahí el nombre del barrio, "Realejo", según M. GÓMEZ MORENO, (1892); Guía de Granada, p. 224.
Almanjarra, dentro del actual Cuarto Real de Santo Domingo, propiedad de la esposa de Muley Hacén y madre de Boabdil. Tras las capitulaciones, todas las huertas y propiedades de esta zona pasaron a manos de los Reyes Católicos quienes las cedieron a la orden de los Dominicos ${ }^{7}$.

A partir del s. XVI, toda la trama urbana de esta área se reformará para adecuarla al gusto y necesidades de la nueva población cristiana. El inmueble que nos ocupa debió de construirse muy próximo a la Puerta del Pescado, que fue demolida en $1840^{8}$. Algunos autores fechan la Puerta del Pescado en el s. XIII, en base a una inscripción árabe escrita en azulejos ${ }^{9}$.

\section{EVOLUCIÓN HISTÓRICA DEL EDIFICIO}

El análisis de los paramentos internos del edificio permitió conocer la existencia de numerosos grafitos realizados sobre la gruesa capa de yeso que reviste los muros. El yeso tiene una tonalidad oscura, debido a la antigüedad, aunque en algunas zonas es completamente de color negro, debido a un antiguo incendio. Cubriendo el revoco de yeso, encontramos numerosas capas de encalado superpuestas unas a otras, donde se suceden diferentes colores.

En general, las características del edificio tales como la distribución del espacio interior en habitaciones transversales, las angostas escaleras abovedadas y el predominio del espacio en vertical sobre el horizontal, sugieren que se trate de un antiguo espacio público, que se ocupa con una construcción adosada a una edificación militar preexistente.

\footnotetext{
${ }^{7}$ Seco de Lucena Paredes, L. (1975): La Granada Nazarí del s. XV. Granada. P. 154.

${ }^{8}$ Gómez Moreno, M. (1892): "Guía de Granada". P. 223. El autor recoge la opinión de D. Martínez de la Rosa, sobre la Puerta del Pescado, el cual la encuentra parecida a la de las Orejas y que en 1833 aún conservaba un embovedado con tres arcos y capilla encima.

${ }^{9}$ Gómez Moreno, M. (1892): “Guía de Granada”. P. 223-224.
} 
La evolución histórica del edificio queda reflejada en el muro medianero. En el extremo sureste han quedado los restos de un edificio con alzado de tapial sobre muro de mampuesto, de Época Moderna, en base a los materiales y la técnica constructiva empleada. La zona baja de dicho muro es de mampuesto encintado, podría formar parte de una cerca de Época Cristiana, que se antepone a la muralla medieval de tapial con el objeto de proteger a las propias murallas del fuego de artillería, nuevo armamento militar que se utilizaba desde el asedio a la ciudad de Granada por parte de los Reyes Católicos.

Sobre la cerca se levantaría un edificio con alzado de tapial. Por la técnica constructiva empleada, es la construcción más antigua y se podría adscribir crono-culturalmente al s.XVI, tras la toma de la ciudad de Granada, dentro de todas las obras de remodelación de la ciudad que llevan a cabo los Reyes Católicos.

Los restos arqueológicos y la documentación escrita apuntan a que el espacio que ocupa el edificio contemporáneo podría estar relacionado con el de la muralla medieval, concretamente con una de las puertas de acceso por la zona sur, la conocida como Puerta del Pescado.

\section{ELEMENTOS ARTÍSTICOS}

En diferentes muros del edificio se han encontrado grafitos históricos de distinta temática ${ }^{10}$, entre los que predominan la representación de barcos, indumentarias que hemos identificado como miriñaques ${ }^{11}$ y cuentas o elementos de cálculo. Los elementos artísticos están realizados sobre el yeso que reviste los paramentos internos, tanto de los muros perimetrales, como de los tabiques de compartimentación interna. El revoco más antiguo es de tonalidad muy oscura, debido a un incendio que se produjo

\footnotetext{
${ }^{10}$ Se han documentado un total de 70 grafitos

${ }^{11}$ Estructura ligera de metal que a modo de falda, se pone bajo los vestidos, de manera que estos quedan con talle muy marcado y amplias faldas.
}

en el tiro de una antigua chimenea. Existen algunos arreglos posteriores, en los que se utiliza revoco de yeso, que mantiene el color claro por ser posterior al incendio. Sobre el enlucido de yeso, se superponen multitud de capas de cal de diferentes colores y tonalidades.

Las incisiones sobre el yeso son finas, realizadas con algún elemento metálico acabado en punta fina, como por ejemplo un clavo o una navaja. La cronología estimada es del s. XIX.

En las paredes de la casa con el número 18 (situada al norte), la segunda planta fue la más afectada por el incendio, de ahí que el revoco de yeso presente un color muy oscuro debido al hollín. En la primera planta y en la planta baja, el incendio sólo afectó a la zona del tiro de la chimenea, por lo que el yeso es de color más claro. En la primera planta predominan los círculos a compás y los elementos de cuentas. En la planta baja no hay grafitos.

Los grafitos se distribuyen por todas las plantas, siendo más numerosos en la Segunda Planta donde, en el Lienzo $1^{12}$, se llegan a realizar 19 grafitos, entre los cuales destacan las representaciones de figuras humanas y barcos. Sin embargo, en la planta baja sólo hay dos grafitos, uno es de círculos a compas y otro de elementos de cuenta, ambos situados en la casa con el número 16 (situada al sur).

La altura a la que se realizan los grafitos varía, aunque en general suele ser superior a $1,50 \mathrm{~m}$ desde el suelo.

Los grafitos se realizaron con posterioridad al incendio en la vivienda, como se desprende de los realizados en las paredes tiznadas, donde las incisiones perpetradas dejan las líneas limpias sobre la superficie previamente ennegrecida.

12 El lienzo 1 se ha conservado en su totalidad, protegiéndose con un trasdosado. 


\section{Metodología de registro}

El primer paso fue la limpieza de los paramentos, retirando con espátulas las numerosas capas de pintura superficial. A continuación se procedió a la identificación de los grafitos, otorgando un número de inventario a cada uno de ellos y referenciando en planimetría la correspondiente ubicación espacial.

Para la documentación gráfica, se realizaron fotografías digitales utilizando diferentes escalas, según se tratase de fotografía general de cada muro o a nivel de detalle con cada grafito. Los parámetros fotográficos se han corregido utilizando un programa informático, que usando técnicas de fotogrametría, nos permite realizar los dibujos utilizando como calco las fotografías a escala milimétrica, sirviéndonos de un software de diseño técnico (AutoCAD).

Por último, se ha creado una base de datos con toda la información descriptiva, tecnológica, gráfica y fotográfica, referente a los grafitos, que sirve para la elaboración de fichas digitalizadas especiales para su documentación y registro.

En cuanto a la conservación de los grafitos, se ha colocado un trasdosado ante los muros originales para proteger un gran lienzo de $7 \mathrm{~m}$. de longitud. Previamente, los grafitos se han protegido con la colocación de un geotextil.

\section{Las figuras humanas}

Las figuras humanas suelen realizarse de manera muy esquemática. Se han considerado como representaciones masculinas aquellas que se expresan con formas geométricas rectangulares para el cuerpo, con las cabezas redondeadas y las piernas realizadas con líneas arqueadas, quizá porque es la forma de representar los pantalones bombachos o metidos por la caña de las botas. Algunos personajes presentan líneas en la cintura o el pecho, que pueden estar haciendo referencia a fajas, correajes y armas.
Las figuras femeninas se distinguen por llevar faldas largas y amplias. Las faldas contienen líneas en vertical y horizontal, que sugieren pueda tratarse de miriñaques o crinolinas, consistentes en una estructura ligera con aros metálicos que mantenía voluminosas las faldas de las damas sin necesidad de usar numerosas enaguas. Se impusieron como moda a partir de 1850, teniendo como impulsora a la emperatriz Eugenia de Montijo.

Las figuras humanas se localizan sólo en la segunda planta de la casa norte, la nํํㅇ. Suele predominar la representación de parejas, constituidas por una figura femenina y otra masculina que parecen estar saludándose o bailando. En algunos grafitos, las figuras humanas tienen más detalle y se les coloca ojos, nariz y cabello. También existen figuras humanas en las cubiertas de los barcos, suelen ser masculinas, con los brazos en alto, a modo de saludo.

\section{Los barcos}

El mar se encuentra a $60 \mathrm{~km}$. de distancia de Granada, por lo que las embarcaciones no se pueden considerar como elementos cotidianos en la vida corriente de los granadinos.

Los barcos representados suelen ser veleros de casco redondeado, de una cubierta con varios palos y no se observan remos, salvo en los botes. Las velas en un caso son cuadradas, en otro triangulares y en los restantes están recogidas. Destacan lo que parece ser el castillo de popa. Sólo un grafiti representa huecos en el casco, aunque no se puede asegurar que sea para la artillería. Algunos grafitos de naves van acompañados de pequeñas barcas con remos.

Las naves son pequeñas, por lo que pensamos que quizá se tratara de embarcaciones para navegación de cabotaje, utilizadas para el traslado de pasajeros, de ahí que en los grafitos no se haga referencia a armamento o a pesca y las escenas hagan alusión a saludos de llegada o de despedida. 
Todo lo anterior nos lleva a pensar que los grafitis no los realizó un soldado, sino una persona que había visitado un puerto para ir a recibir o a despedir a alguien. Por ello, las escenas contienen personajes que saludan con las manos y botes de remos junto a los barcos, sin alusiones a las armas o a actividades de pesca. Los barcos sólo se localizan en la segunda planta del inmueble situado al norte.

También hay representaciones individuales de elementos de navegación, es el caso de un ancla situada en un muro de la primera planta. Es un ancla tipo almirantazgo, sin cepo. Tiene los dos brazos con los extremos terminados en una superficie sensiblemente plana, acabada en punta, y la caña central rematada con el hueco del arganeo, donde enganchaba la cadena.

Es otro elemento que ofrece una cronología relativa, ya que este tipo de ancla aparece a finales del s. XVIII, que es cuando los brazos adquieren una forma curvada característica con dimensiones y forma determinadas. Ese tipo de ancla pasó a llamarse ancla patente del Almirantazgo, típica de la segunda mitad del s. XIX, y que deja de utilizarse a finales del s. XIX. Son de metal, generalmente de hierro, con la caña y los brazos conformados en una sola pieza.

\section{Elementos de contabilidad}

En la primera planta predominan los elementos de contabilidad. No todas las personas que realizaron los grafitos conocían los números, por lo que existen diferentes formas de apuntar cantidades, utilizando signos que hacen la función de cifras. Es por esto que encontramos diferentes procedimientos para ayudarse a contar, sumar y restar utilizando elementos de muy diverso tipo, como por ejemplo las cuentas con "palotes", consistentes en líneas bien organizadas en franjas horizontales y verticales o líneas que cuelgan de una línea horizontal.

Para agilizar las cuentas, utilizan agrupamientos con valores distintos representados por líneas cruzadas a modo de X, así como círculos y elementos semicirculares o triangulares dispuestos en línea. También existen cuentas con números de una, dos y tres cifras.

En la primera planta predominan los círculos a compas. Los hay de diferentes diámetros, vacíos o conteniendo otros círculos a modo de decoración, que puede ser en forma de pétalos, cruces o dispuestos en superposición, creando figuras geométricas a partir de un círculo a compas en cuyo interior hay flores de seis pétalos, de cuatro pétalos y cruces.

\section{Inscripciones}

Recogemos en este apartado los escritos grabados en los muros. Son muy escuetos y consisten en firmas, números que no forman parte de cuentas y frases repetidas. Sabemos que algunas firmas las hicieron utilizando agujas gruesas, que se han encontrado metidas en pequeños agujeros de la pared, generados al colgar objetos como perchas, cuadros o estantes. Resulta muy complicado discernir qué nombres y apellidos hay escritos, pensamos que se trata de firmas porque cada palabra comienza con mayúscula, como si se tratara de un nombre propio, y están hechos con buena caligrafía.

Se puede conocer el contenido de cuatro frases que se repiten y se colocan una debajo de otra: "PADRE ALBA".

Uno de los escritos está muy garabateado y se puede leer la palabra "PAJA".

En otro escrito también se distinguen las palabras "13-TOMO12".

El haber tenido pegada en la pared alguna estampa religiosa, ha hecho que queden algunos trozos adheridos al yeso y que se puedan distinguir claramente algunas letras, quizá refiriéndose a la virgen Inmaculada:

\section{INMACULADA \\ SIN MANCHA DE PECADO ORIGINAL}

Hay unos números bien legibles, que quizá hagan referencia a alguna fecha, los 
dos primeros dígitos están grabados en un tamaño menor que los otros dos: "16 38"

Por último, hay que hacer referencia a un intento de grabar una fecha en el muro lateral de una ventana, aunque sólo pusieron las palabras "año" y "día": AÑODÍA, todo junto y sin rotular los números.

\section{Otras representaciones}

Otros elementos representados son corazones, lágrimas, una cruz, un elemento de juego y otro arquitectónico.

Uno de los corazones parece tener una cruz latina en el centro; es una representación del Sagrado Corazón de Jesús, que en la segunda mitad del siglo XIX está en boga, produciéndose un auténtico culto al mismo. Su aceptación fue tanta, que el papa León XIII declaró su consagración en 1899.

La cruz es latina, formada por dos segmentos rectangulares. El punto de intersección de los dos rectángulos forma un pequeño cuadrado.

También hay una representación de tipo lúdico que hemos interpretado como un Alquerque, o tablero para el juego de "tres en raya".

Por último, hay que hacer mención a la representación de un elemento arquitectónico; se trata de una puerta con arco, alfiz y línea de imposta decorada.

\section{CONCLUSIONES}

Se han analizado y documentado un amplio conjunto de grafitos históricos que aportan información sobre la cultura popular del s. XIX. Estos elementos culturales se han encontrado en un inmueble situado en el casco histórico de Granada, en el popular barrio del Realejo.

El inmueble está formado por dos casas. Sufrió un incendio que se produjo en el tiro de la chimenea y que afectó principalmente a la casa situada al norte, con el oㅡ 18 . Tras el incendio, el inmueble debió quedar abandonado algún tiempo, momento en que se realizan los grafitos de barcos y figuras humanas, ya que las incisiones dejan líneas claras sobre la superficie negra de hollín. Al poco tiempo se acometen obras de acondicionamiento y mejora de la vivienda, eliminando la chimenea; es entonces cuando se realizan los grafitos con motivos de contabilidad y de circulos a compás, posiblemente realizados por los albañiles y operarios encargados de las obras, al ajustar jornales, materiales de construcción o jornadas de trabajo.

De las personas que realizaron los grafitos sabemos muy poco, pero está claro que hay más de una autoría. La altura a la que se realizan los grafitis es variada, pero en general suelen estar a partir de 1,50m desde el suelo. Esta es una de las razones para pensar que no son niños pequeños los autores de estos grafitis. Apenas hay agrupaciones de grafitis y son muy pocas las superposiciones. Tampoco se han conservado fechas, aunque hay una inscripción que pone "Año-Día" sin cifra alguna.

Las figuras humanas son representaciones esquemáticas y no reproducciones, con un bajo nivel de mérito artístico y donde se acentúa lo que se considera importante; de ahí que en los dibujos de barcos, tenga tanta categoría el barco como las personas que están en cubierta, sin respetar demasiado la perspectiva o la escala, quizá atendiendo a una clara intencionalidad narrativa.

Algunos de los grafitos de barcos parecen ser naves de cabotaje. Da la impresión de que el autor no conoce bien los barcos, sino más bien que ha visto desde tierra las naves llegar y partir: en esos momentos se producen las escenas de saludos y despedidas, anclas que se levan, botes empleados para llegar a tierra. Se trata de un testigo, que ha asistido al recibimiento de algún familiar o a su despedida, en algún puerto de la costa cercana, dejando plasmado en sus grafitos las dos cosas que más le han impresionado, los barcos como medio de transporte y las escenas de saludos, tanto por despedida o reencuentro de familiares que corren a abra- 
zarse, como los aspavientos de los pasajeros desde los barcos.

En cuanto a la cronología de los grafitos, podemos hacer una datación relativa basada en el tipo de ropa femenina representada y en el tipo de elementos de navegación como las anclas. Los miriñaques se ponen de

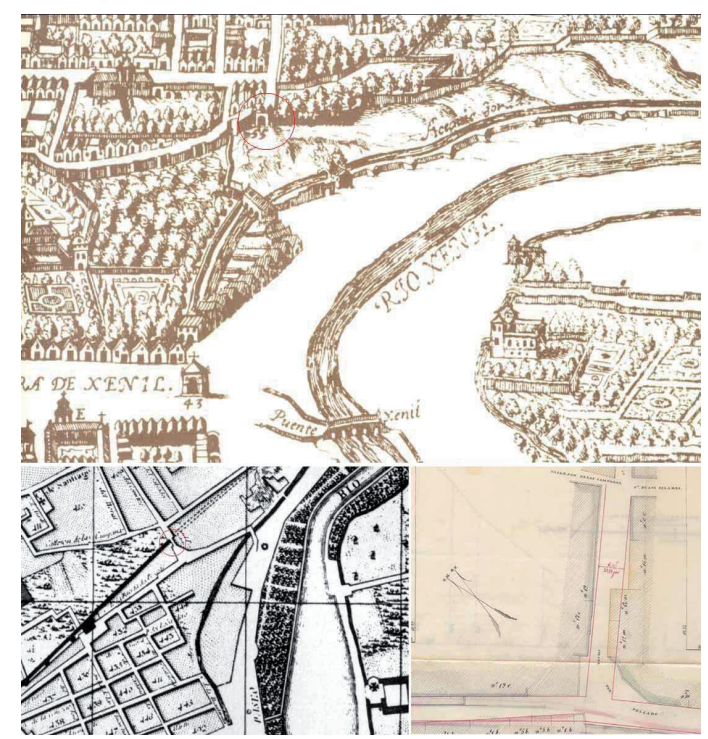

- Fig. 1. Plataforma de Vico; Plano de Dalmau y Proyecto de alineamiento de 1869. moda casi al mismo tiempo que las anclas tipo almirantazgo, a partir de la segunda mitad del s.XIX, por tanto los grafitos, en tanto que representan aquello que ven, nos ofrecen datos sobre la moda femenina y los adelantos en la navegación de la segunda mitad del s.XIX.

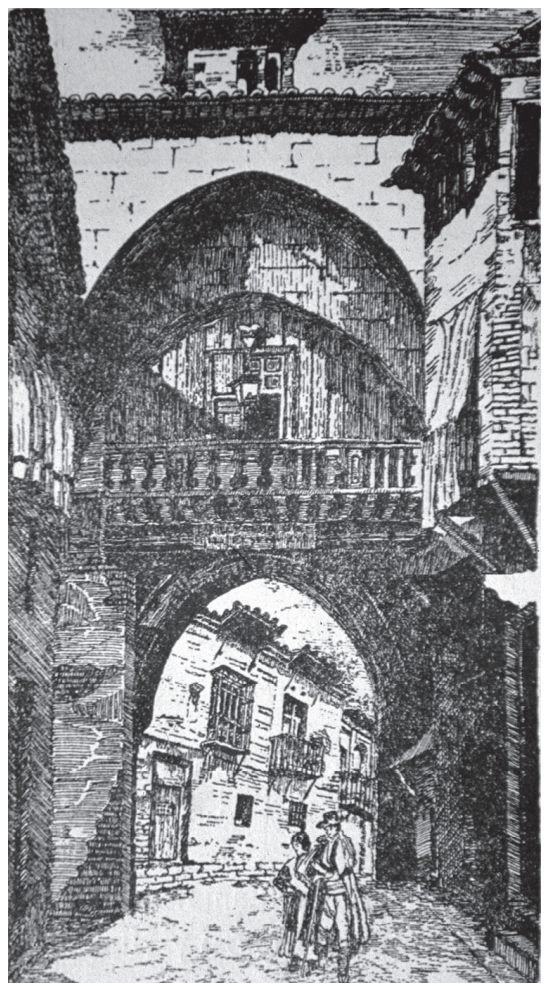

- Fig. 2. Grabado de la Puerta del Pescado

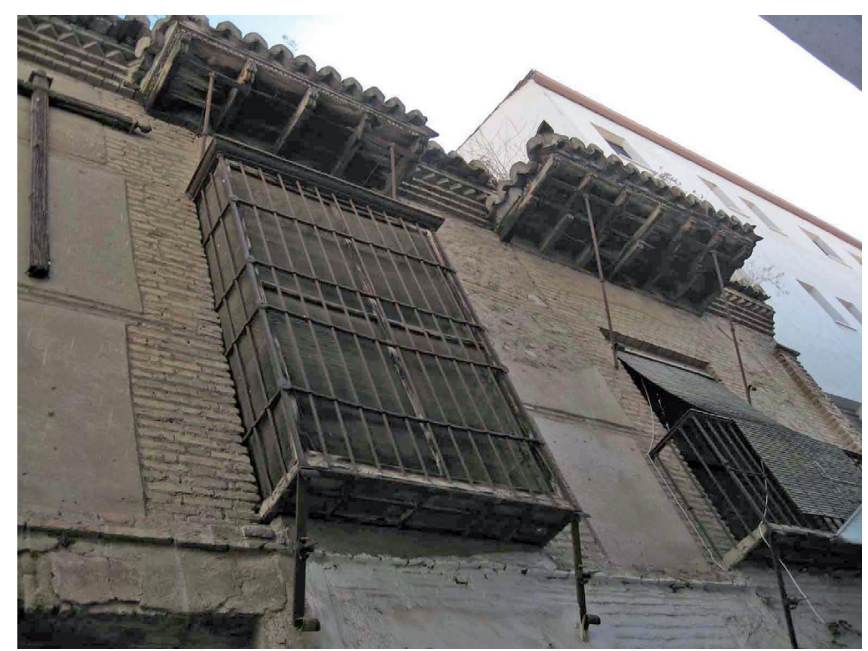

- Fig. 3. Fachada representada en el grabado. 


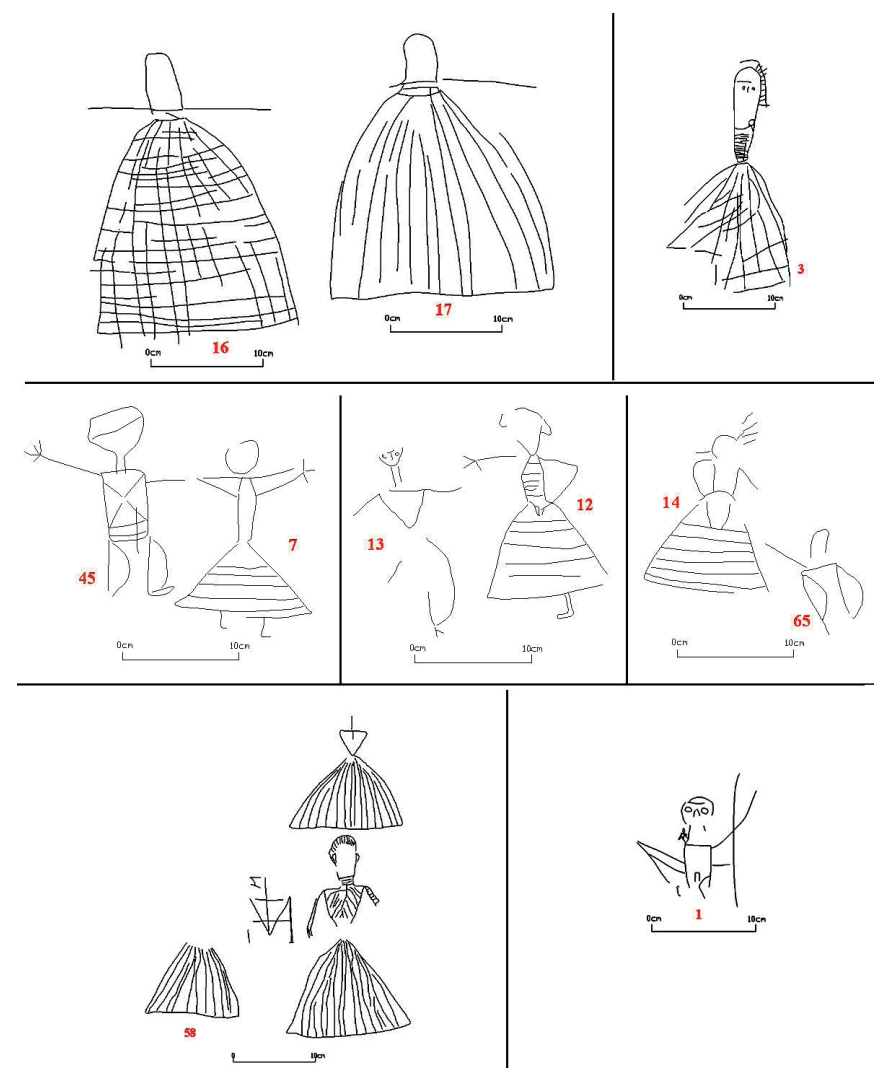

- Fig. 4. Representación de miriñaques. Parejas y figura masculina.

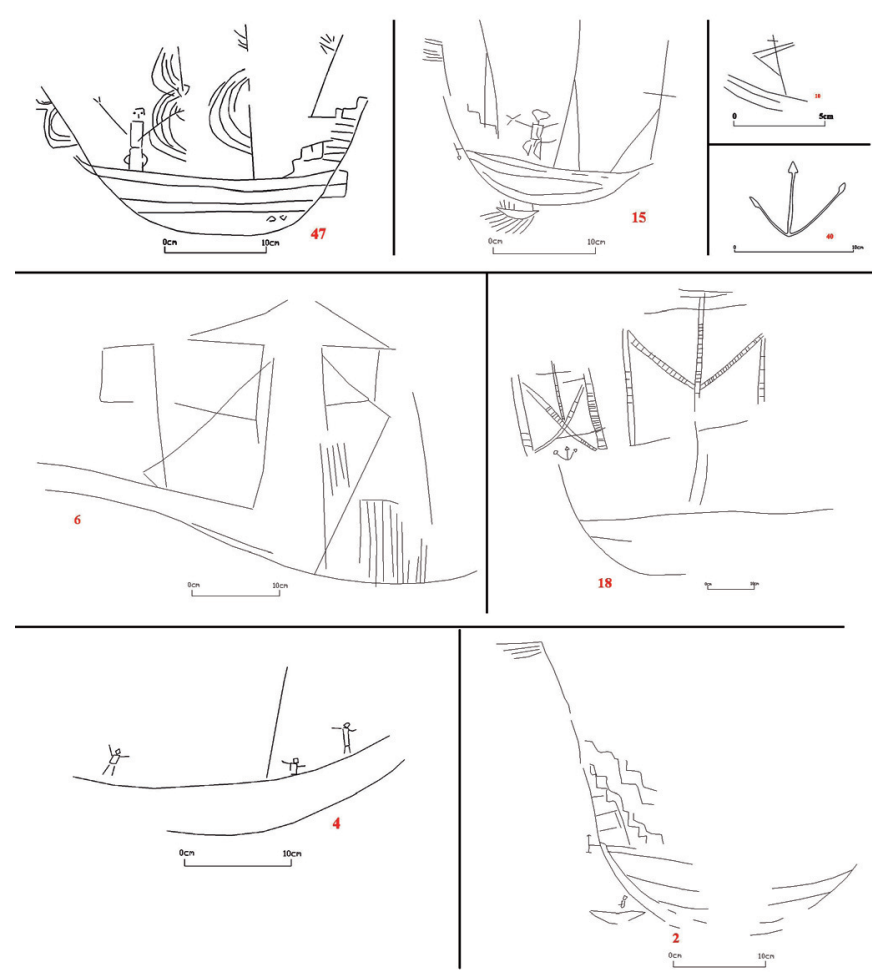

- Fig. 5. Barcos con personajes a bordo que saludan. 


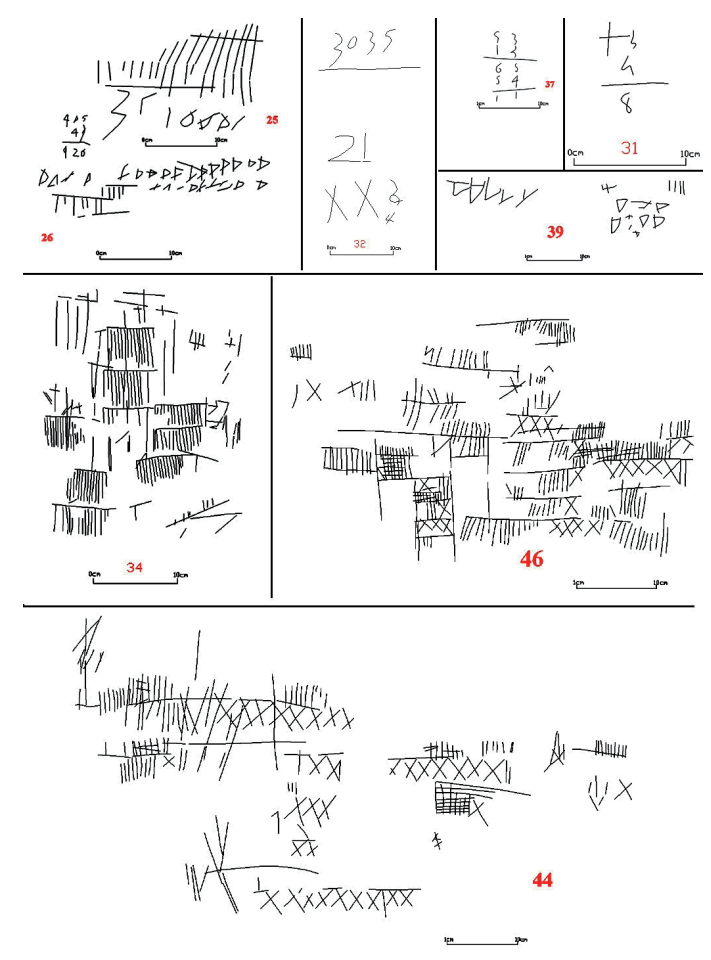

- Fig. 6. Lámina I de elementos para contar.

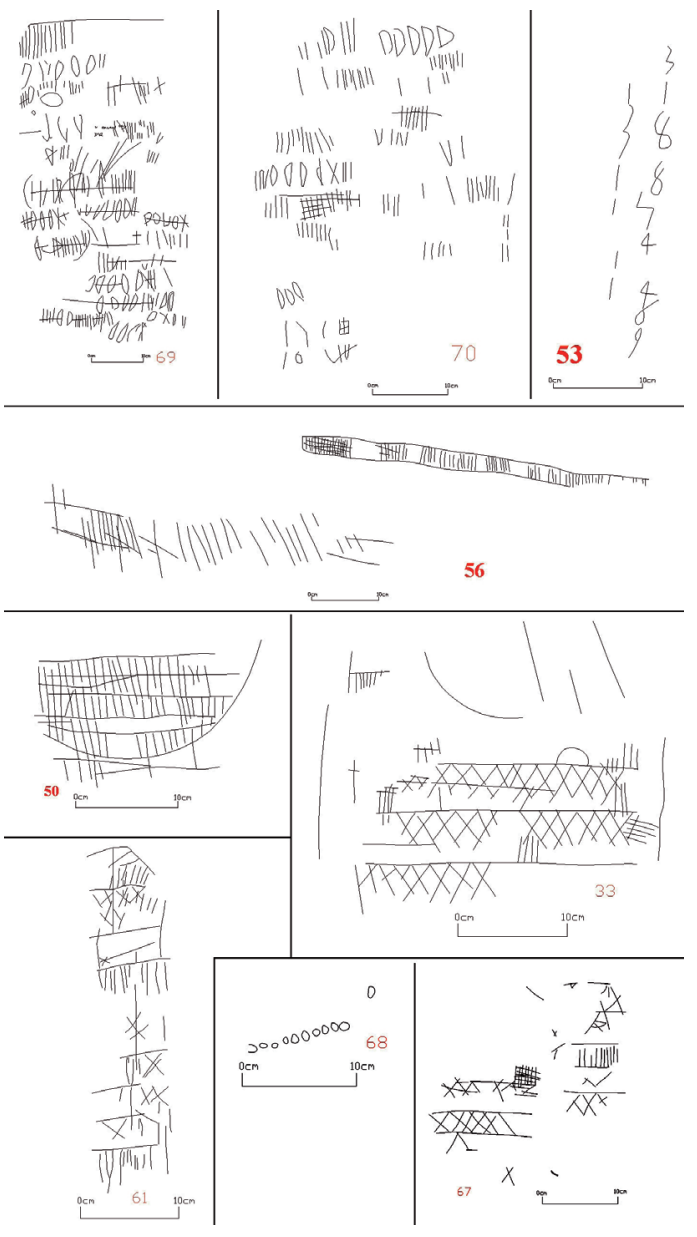

- Fig. 7. Lámina II de elementos de contabilidad. 


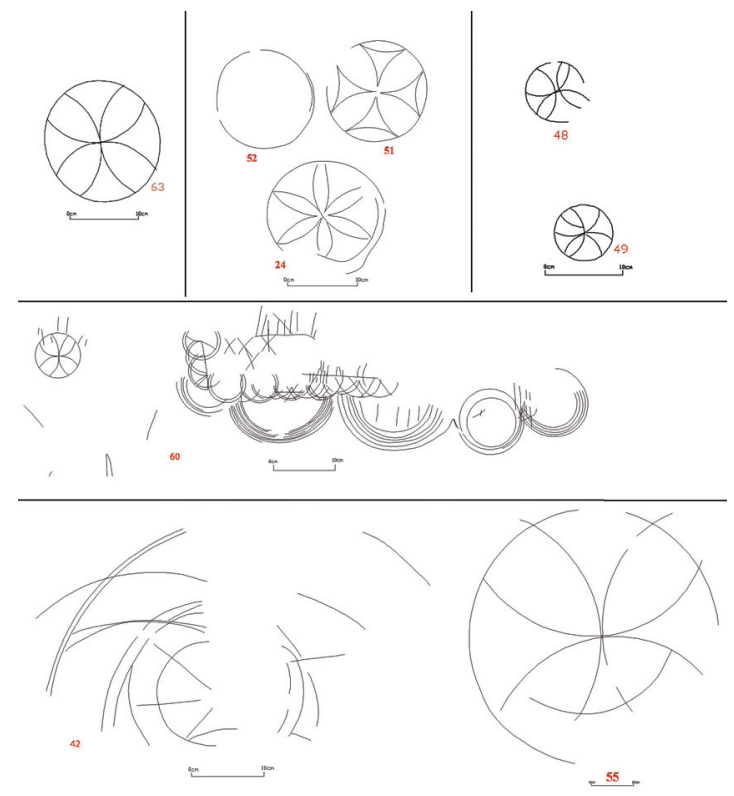

- Fig. 8. Figuras realizadas con compás.

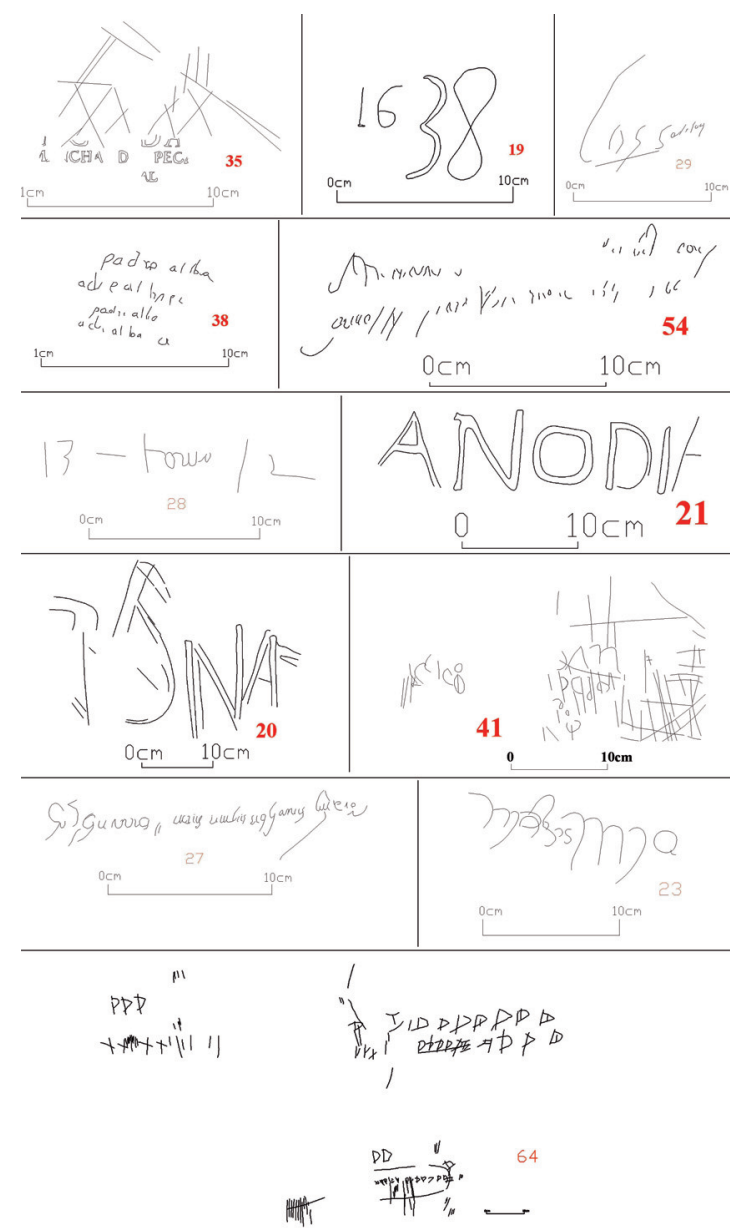

- Fig. 9. Firmas, frases y otras inscripciones. 


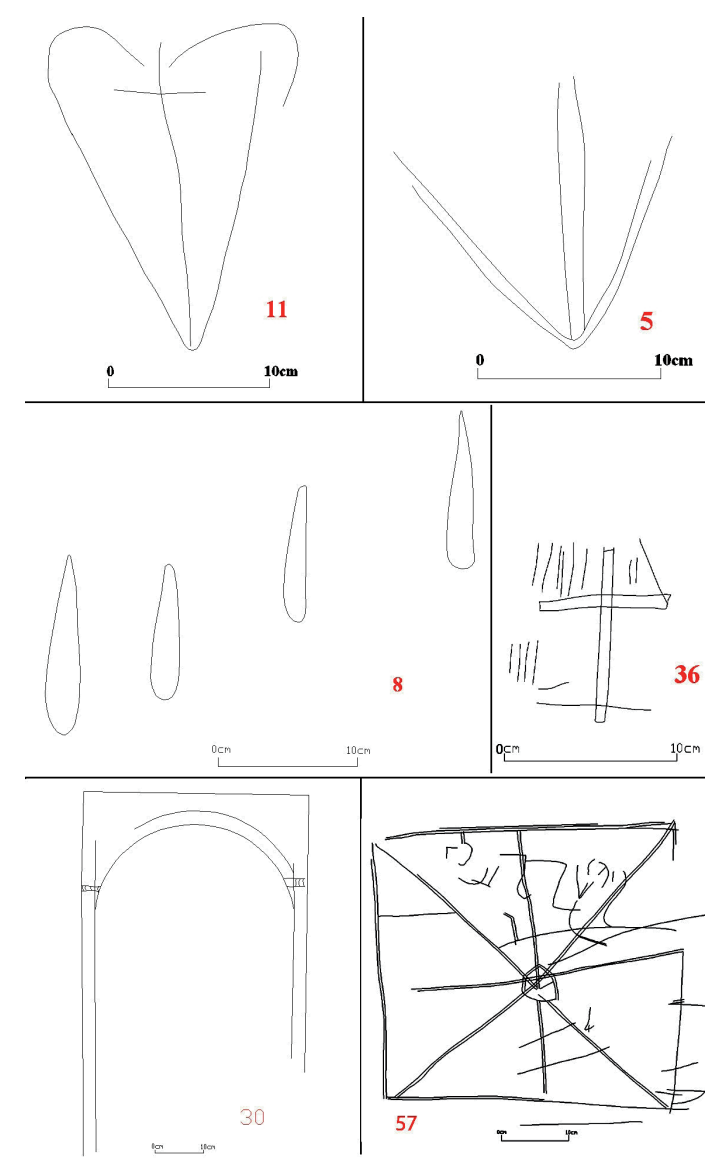

- Fig. 10. Representaciones de corazones, lágrimas, arco y cruz.

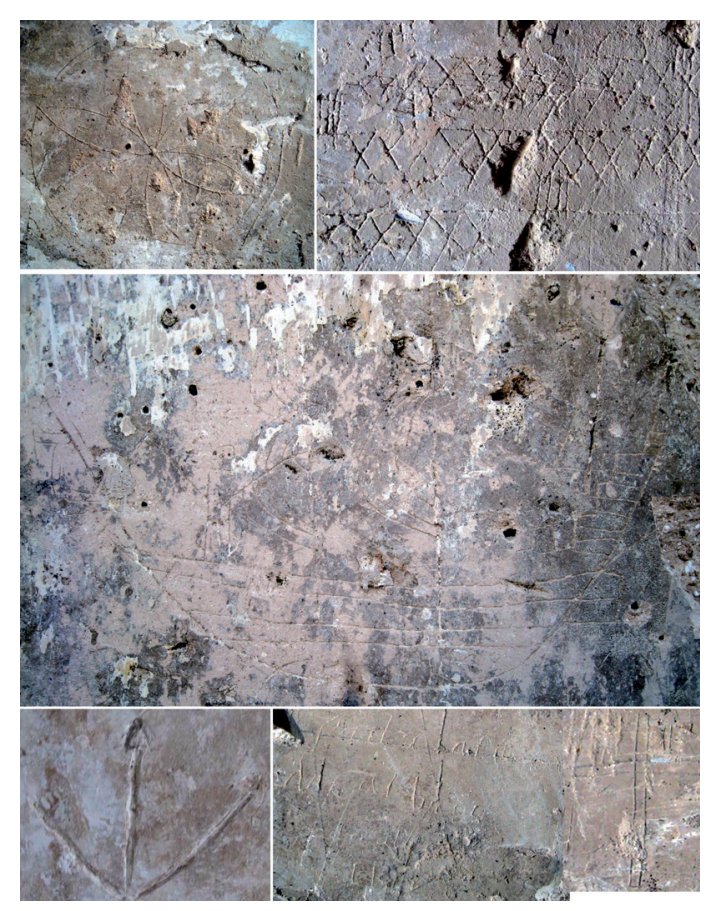

- Fig. 11. Fotografías de algunos grafitos.

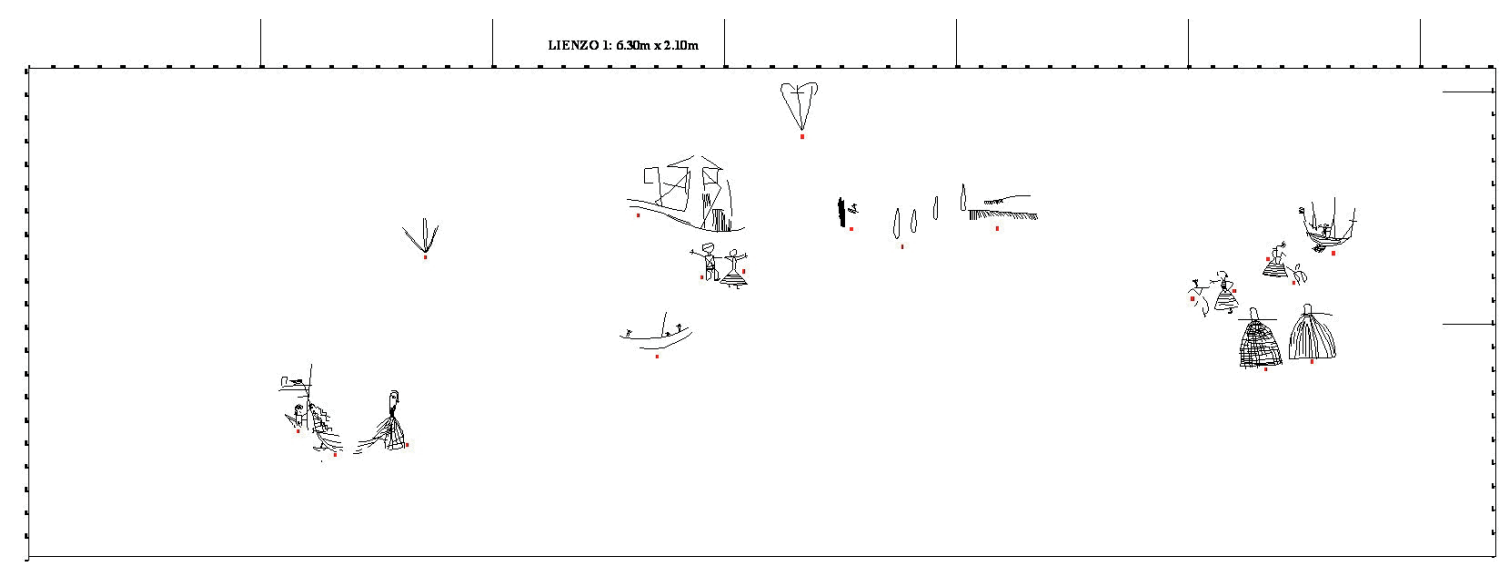

- Fig. 12. Lienzo 1, escalado. 